\title{
A Systematic Review and Meta-analysis of the Combination of Vinorelbine and Lapatinib in Patients With Her2-positive Metastatic Breast Cancer
}

\author{
ATHINA STRAVODIMOU ${ }^{1}$ and IOANNIS A. VOUTSADAKIS ${ }^{2,3}$ \\ ${ }^{1}$ Department of Medical Oncology, Centre Hospitalier Universitaire Vaudois, Lausanne, Switzerland; \\ ${ }^{2}$ Algoma District Cancer Program, Sault Area Hospital, Sault Ste. Marie, ON, Canada; \\ ${ }^{3}$ Division of Clinical Sciences, Northern Ontario School of Medicine, Sudbury, ON, Canada
}

\begin{abstract}
The development of effective human epidermal growth factor receptor 2 (HER2)-targeted therapies has been heralded as a significant milestone in breast cancer treatment, resulting in improvement of the outcome for those with HER2positive metastatic breast cancer. Despite these advantages, metastatic breast cancer is still regarded as an incurable disease. In heavily pretreated patients with increasingly limited options for palliative management, ensuring control of disease and maintenance of quality of life is an important goal. Vinorelbine and lapatinib is a combination used in laterline treatment of metastatic HER2-positive breast cancer. The current article presents a systematic review and meta-analysis of prospective series of the vinorelbine/lapatinib doublet for efficacy and toxicity in metastatic HER2-positive breast cancer. Altogether seven prospective trials involving 235 evaluable patients were retrieved for analysis. Pooled estimates of response rate and disease control rate were $24.4 \%$ and $63.3 \%$ respectively. Furthermore, overall survival was 20.1 months and progression-free survival was 5.44 months. The most common grade 3 and 4 toxicities were seen in fewer than $10 \%$ of cases. Vinorelbinel lapatinib combination regimen may serve as an option for pre-treated patients with metastatic HER2-positive breast cancer.
\end{abstract}

This article is freely accessible online.

Correspondence to: Ioannis A. Voutsadakis, MD, Ph.D., Division of Medical Oncology, Sault Area Hospital, 750 Great Northern Road, Sault Ste Marie, ON P6B 0A8, Canada. E-mail: ivoutsadakis@yahoo.com/ivoutsadakis@nosm.ca

Key Words: Breast cancer, metastatic, HER2-positive, vinorelbine, lapatinib, chemotherapy, meta-analysis, review.
Metastatic breast cancer is the leading cause of death among women worldwide, accounting for approximately half a million deaths per year (1). Overexpression and gene amplification of human epidermal growth factor receptor type 2 (HER2/neu, ERBB2), observed in about $15-20 \%$ of breast cancer cases, is an adverse prognostic indicator associated with aggressive histopathological parameters and poor prognosis, compared with other subgroups (2). The principal goal of current therapies for the treatment of metastatic breast cancer is to seek longer progression-free (PFS) and overall (OS) survival, as well as better symptom relief without increasing toxicity or compromising the quality of life.

Therapeutic strategies have been developed to block HER2 signaling pathways, intracellularly as well as extracellularly, in order to improve the treatment of this cancer, representing probably the most successful story of individualized therapy in breast cancer. Trastuzumab, the first anti-HER2 drug approved for the treatment of metastatic HER2-positive breast cancer demonstrated a significant improvement of PFS and OS (3). However, not all patients benefit from trastuzumab and in some others the disease progresses after initial benefit. This led to second-generation studies in metastatic disease and resulted in the approval of other HER2-targeted therapies, such as lapatinib, an oral, small-molecule drug, reversibly inhibiting the adenosine triphosphate binding site located within the intracellular kinase domain of HER2 receptor. The combination of lapatinib with capecitabine was compared to capecitabine alone in patients previously treated with anthracyclines, taxanes and trastuzumab in the EGF100151 trial and showed the superiority of the combination therapy in terms of time to progression and PFS (4). Even though currently the survival rates in metastatic HER2-positive breast cancer are almost 5 years, the persisting high toll of deaths calls for continued new therapies and combinations. 


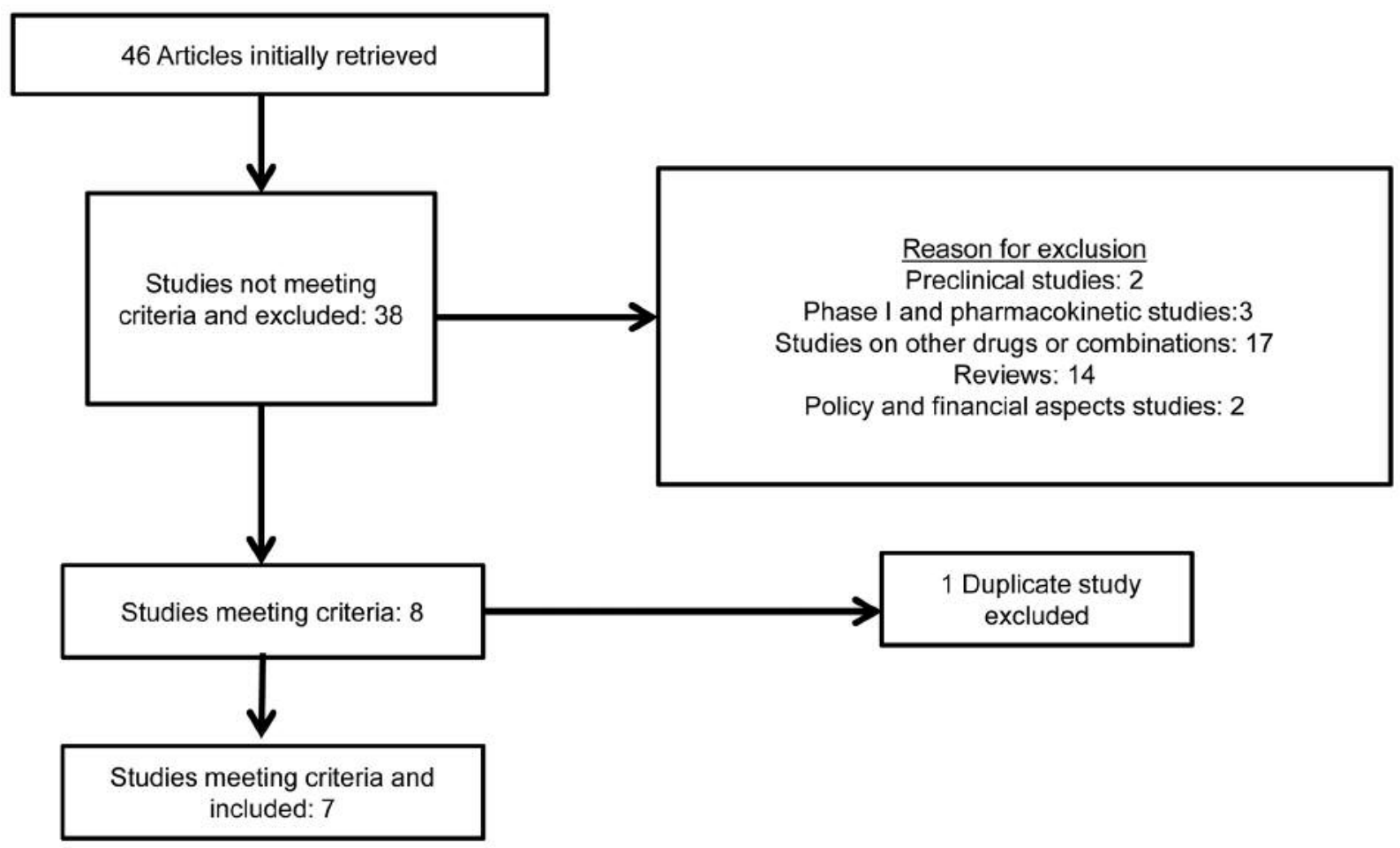

Figure 1. Flow diagram of studies retrieved, excluded and included in this systematic review and meta-analysis.

The association of lapatinib with vinorelbine, another agent with known activity in combination with trastuzumab in metastatic HER2-positive breast cancer, has been evaluated in phase II trials and case series and shown activity in terms of response rates $(\mathrm{RR})$ and disease control rate (DCR) $(5,6)$. In the current study, we performed a systematic review and metaanalysis of lapatinib-vinorelbine-based therapies for the treatment of metastatic HER2-positive breast cancer.

\section{Materials and Methods}

The Medline/Pubmed database (www.ncbi.nlm.nih.gov/pubmed), the EMBASE (Excerpta Medica) database and the Cochrane Central Register of Controlled Trials were searched using the terms "lapatinib", "vinorelbine" and "metastatic breast cancer". Titles of articles retrieved were subsequently checked for relevance and abstracts of articles with relevant titles were further confirmed for inclusion and then retrieved as full texts including available supplementary material. Clinical studies included in this systemic review and meta-analysis discuss patients with metastatic HER2-positive breast cancer who received a combination of vinorelbine and lapatinib in any line of therapy and were evaluated for at least one of the following efficacy outcomes: RR, DCR, PFS or OS. Studies with any type of design (retrospective or prospective) were included. The plan was to include all studies published in English and French language but only studies in English were retrieved with the search criteria and no studies were excluded due to language. A manual search was performed of the reference list of included studies to locate additional relevant publications.
Information that was extracted from the selected articles included demographic data and characteristics of the population studied such as age of the patients, Eastern Cooperative Oncology Group performance status, number and type of previous lines of chemotherapy treatment, number and sites of metastatic disease, stage at presentation (local disease versus de novo metastatic disease), and estrogen receptor status. Efficacy outcomes (RR, DCR, PFS and OS) with 95\% confidence intervals (95\% CIs) as well as adverse effects data were also extracted. Risk of bias in the included studies was assessed with the Risk of Bias in Non-Randomized Studies of Interventions (ROBINS-I) assessment tool (7).

Extracted data on patient characteristics and outcome measures were tabularized and descriptive statistics were calculated. Due to missing characteristics and outcomes of interest in some studies, some estimates were based on only part of the studies. Data on the number of studies from which each characteristic and outcome of interest was derived, as well as the total number of patients each calculation was based on, were recorded and presented in tabularized form. Statistical tests for assessment of heterogeneity among the studies included Cochran's Q test and I2 test. For outcomes for which the heterogeneity between studies was low, the fixed-effect model was used. Conversely, when heterogeneity was high, data were recalculated using a randomeffect model (8). Calculations were performed in Excel (Microsoft Corp., Redmond, WA, USA) as previously described with some modifications (9) and confirmed with the open-source online software Open Meta-analyst, available from Brown University, Providence, RI (www.cebm.brown.edu/openmeta/) (10). Statistical calculations were performed with an online tool (Social Science Statistics, www.socscistatistics.com). 
Table I. Studies included in this meta-analysis.

\begin{tabular}{|c|c|c|c|c|c|c|}
\hline Study (Reference) & Year of publication & Country & Form of vinorelbine & Patients (n) & RR (\%) & $\operatorname{DCR}(\%)$ \\
\hline Saip et al. (17) & 2013 & Turkey & IV & 25 & 16.0 & 56.0 \\
\hline Chan et al. (15) & 2014 & Australia & IV & 19 & 12.5 & 81.25 \\
\hline Chew et al. (16) & 2014 & U.S.A. & IV & 44 & 40.9 & 72.72 \\
\hline Janni et al. (11) & 2015 & Europe & IV & 75 & 23.07 & 76.92 \\
\hline Thalinger et al. (18) & 2016 & Central Europe & IV & 9 & 11.1 & 44.44 \\
\hline Gomez et al. (13) & 2016 & Latin America & IV & 45 & 53.3 & 73.33 \\
\hline Chen et al. (14) & 2018 & Taiwan & $\mathrm{PO}$ & 46 & 19.35 & 38.7 \\
\hline
\end{tabular}

PO: Per os; IV: intravenous; RR: response rate; DCR: disease control rate.

No funding was received from any source for the performance of this systematic review and meta-analysis.

\section{Results}

The initial search retrieved 46 articles published from 2008 to 2018 (Figure 1). Among these, further review selected seven articles that fulfilled the inclusion criteria and were retained for inclusion in the meta-analysis. Reasons for exclusion of retrieved articles included review format (14 articles), articles reporting on other drugs or combinations (17 articles), phase I and pharmacokinetics studies (three articles), articles referring to policy and financial considerations (two articles) and studies concerning pre-clinical evaluations (two articles). From the eight remaining reports, two concerned the same study $(11,12)$ and thus the total number of studies included in the analysis was seven $(11,13-18)$.

Studies included were performed across the globe in all continents except Africa and were published from 2013 to 2018 (Table I). All seven studies were prospective. Four studies had a one-arm phase II multicenter design. Two studies were randomized multicenter phase II trials and the vinorelbine/lapatinib arm that was included in the current meta-analysis was compared to capecitabine/lapatinib in the one (11) or to capecitabine/lapatinib and gemcitabine/ lapatinib in the other that was a three-arm study (13). The seventh study included in the analysis was a phase I/II study (14). Patients in the phase I part of this study were not included in the outcome analysis. All studies used intravenous vinorelbine but one, which used oral vinorelbine (14). The total number of patients included in the seven studies was 267 and ranged from nine to 75 patients (Table II). The dose of lapatinib was $1,250 \mathrm{mg}$ daily in five studies $(11,13,15,17,18), 1,500 \mathrm{mg}$ daily in one study $(16)$, and $1,000 \mathrm{mg}$ daily in the study that was also the only one that used oral vinorelbine (14). In this latter study, the dose of oral vinorelbine was $50 \mathrm{mg} / \mathrm{m}^{2}$ on days 1 and 8 of a 3 -week cycle and was escalated to $60 \mathrm{mg} / \mathrm{m}^{2}$ after the first cycle in 11 patients (14). In the six studies that used intravenous vinorelbine, the dose was $20 \mathrm{mg} / \mathrm{m}^{2}$ on days 1 and 8 of a 3-
Table II. Baseline characteristics of patients from the studies included. In some studies, the characteristic of interest was not reported.

\begin{tabular}{|c|c|c|c|}
\hline & $\begin{array}{c}\text { Patients } \\
(\mathrm{n}=267) \\
\mathrm{n}(\%)\end{array}$ & $\begin{array}{c}\text { Total } \\
\text { patients } \\
\text { with data, } \mathrm{n}\end{array}$ & $\begin{array}{c}\text { Studies } \\
\text { with } \\
\text { data, n }\end{array}$ \\
\hline \multicolumn{4}{|l|}{ Age, years } \\
\hline Median (range) & $51.7-56(26-84)$ & 267 & 7 \\
\hline \multicolumn{4}{|l|}{ ECOG PS } \\
\hline $0-1$ & $174(93 \%)$ & 187 & 6 \\
\hline $2-3$ & $13(7 \%)$ & & \\
\hline \multicolumn{4}{|l|}{ Prior lines of chemotherapy, $\mathrm{n}$} \\
\hline 0 & $112(55.2 \%)$ & 203 & 7 \\
\hline 1 & $53(26.1 \%)$ & & \\
\hline 2 & $19(9.4 \%)$ & & \\
\hline 3 & $12(5.9 \%)$ & & \\
\hline$\geq 4$ & $7(3.4 \%)$ & & \\
\hline \multicolumn{4}{|l|}{ Type of prior chemotherapy } \\
\hline Anthracycline & $35(61.4 \%)$ & 57 & 3 \\
\hline Taxane & $25(43.9 \%)$ & 57 & 3 \\
\hline Capecitabine & $9(100 \%)$ & 9 & 1 \\
\hline Trastuzumab & $135(63.1 \%)$ & 214 & 5 \\
\hline Any prior chemotherapy & $179(75.2 \%)$ & 238 & 6 \\
\hline \multicolumn{4}{|l|}{ Organs involved, $\mathrm{n}$} \\
\hline $1-2$ & $76(64.4 \%)$ & 118 & 4 \\
\hline$\geq 3$ & $42(35.6 \%)$ & & \\
\hline \multicolumn{4}{|l|}{ Sites involved } \\
\hline Visceral & $99(88.4 \%)$ & 112 & 3 \\
\hline Non-visceral only & $13(11.6 \%)$ & & \\
\hline \multicolumn{4}{|l|}{ Presentation } \\
\hline Recurrent disease & $201(75.3 \%)$ & 267 & 7 \\
\hline Metastatic de novo & $60(22.5 \%)$ & & \\
\hline Unknown & $6(2.2 \%)$ & & \\
\hline \multicolumn{4}{|l|}{ ER status } \\
\hline Positive & $135(50.6 \%)$ & 267 & 7 \\
\hline Negative & $132(49.4 \%)$ & & \\
\hline
\end{tabular}

ECOG PS: Eastern Cooperative Oncology Group Performance Status; ER: estrogen receptor.

week cycle except for one study that used a dose of 25 $\mathrm{mg} / \mathrm{m}^{2}$ on days 1 and 8 of a 3 -week cycle (17).

Risk of bias was estimated to be moderate to high mostly due to the non-randomized, open-label design of five of the studies and randomized but also open-label design in the remaining two 


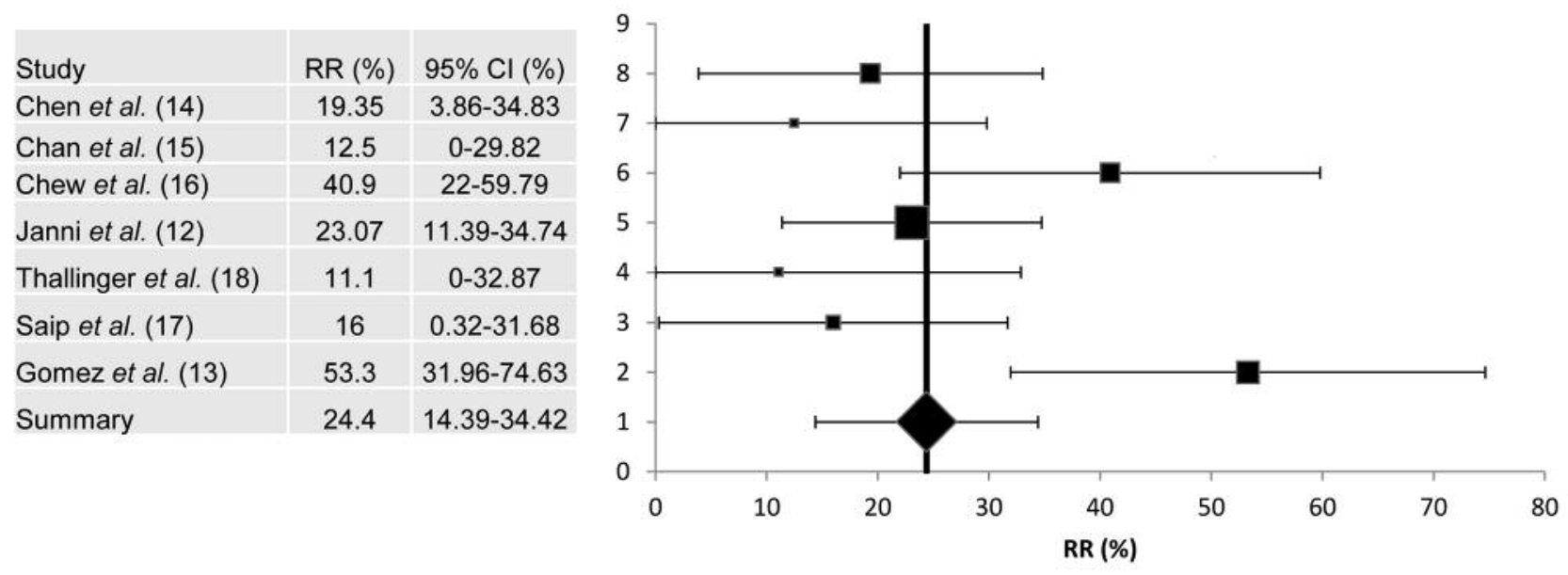

Figure 2. Meta-analysis of response rates (RR) with their $95 \%$ confidence intervals (CI) of the seven studies included. Data of a total of 235 patients were analyzed. The summary $R R$ was $24.4 \%(95 \% C I=14.39-34.42 \%)$.

\begin{tabular}{|l|c|c|}
\hline Study & DCR (\%) & $95 \% \mathrm{Cl}(\%)$ \\
\hline Chen et al. (14) & 38.7 & $16.8-60.6$ \\
\hline Chan et al. (15) & 81.25 & $37.1-100$ \\
\hline Chew et al. (16) & 72.72 & $47.5-97.9$ \\
\hline Janni et al. (12) & 76.92 & $55.6-98.2$ \\
\hline Thallinger et al. (18) & 44.44 & $0.1-88$ \\
\hline Saip et al. (17) & 56 & $26.7-85.3$ \\
\hline Gomez et al. (13) & 73.33 & $48.3-98.3$ \\
\hline Summary & 63.38 & $50.39-76.37$ \\
\hline
\end{tabular}

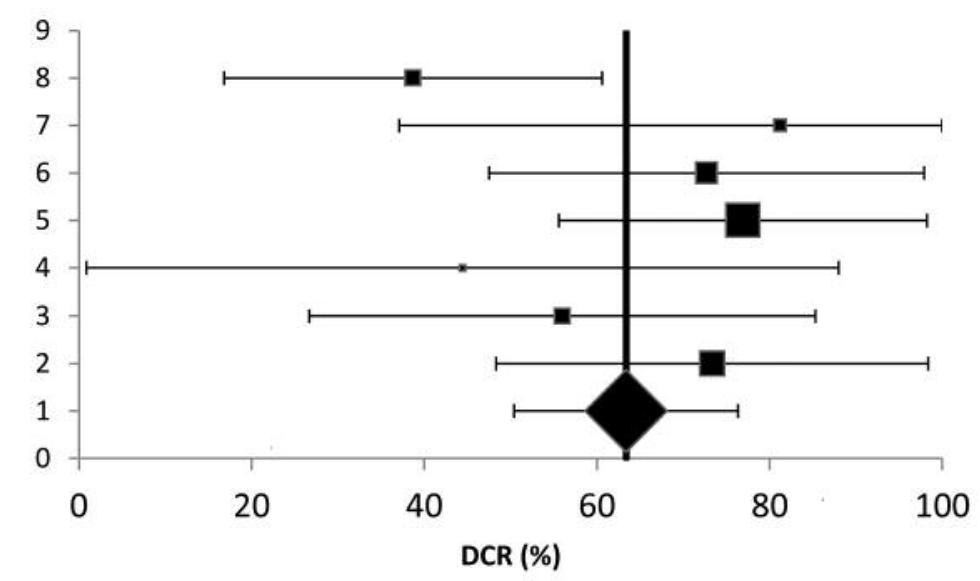

Figure 3. Meta-analysis of disease control rates (DCR) with $95 \%$ confidence intervals (CI) of the seven studies included. Data of a total of 235 patients were analyzed. Overall, the DCR was $63.38 \%$ (95\% CI=50.39-76.37\%).

studies. Domains with risk of confounding included baseline confounding characteristics, bias in selection of participants, and bias in evaluation of outcomes. Regarding RR, a combined estimate was based on 235 evaluable patients from all seven studies. The meta-analysis revealed a significant heterogeneity between studies, with a Q value of $14.72(p=0.02)$ and I2 of 59.2. Thus, a random-effect model was used. The estimated RR was $24.4 \%$ (95\% CI=14.39-34.42\%) (Figure 2).

Estimation of DCR was based on the same 235 evaluable patients from the seven studies. Heterogeneity between studies was intermediate $(\mathrm{Q}=9.15, p=0.12, \mathrm{I} 2=34.5)$ and a randomeffect model was preferred for the analysis. The summary DCR estimate was $63.38 \%$ (95\% CI=50.39-76.37\%) (Figure 3).

The PFS estimate was based in 267 patients from all seven studies. Heterogeneity between studies was high $(\mathrm{Q}=15.9$, $\left.p=0.01, \mathrm{I}^{2}=62.5\right)$ and a random-effect model was retained.
The summary PFS was 5.44 months (95\% CI=4.47-6.42 months) (Figure 4).

Six studies provided information on OS but the median OS was not reached in one of them (14). As a result, the summary estimate for OS was based on five studies and a total of 177 patients. Heterogeneity between studies was intermediate $(\mathrm{Q}=6.94, p=0.13, \mathrm{I} 2=42.3)$ and a random-effect model was also preferred for the analysis on this occasion. The summary OS was 20.12 months (95\% CI=15.54-24.71 months) (Figure 5).

The most common adverse effects of all grades observed in the seven studies included diarrhea (64.7\% of patients), nausea (63.1\% of patients), neutropenia (57.3\% of patients) and asthenia or fatigue ( $41.2 \%$ of patients) (Table III). The most common grade 3 and 4 adverse effect was neutropenia $(32.5 \%$ of patients). All other grade 3 or 4 adverse effects were observed in fewer than $10 \%$ of patients and most commonly 


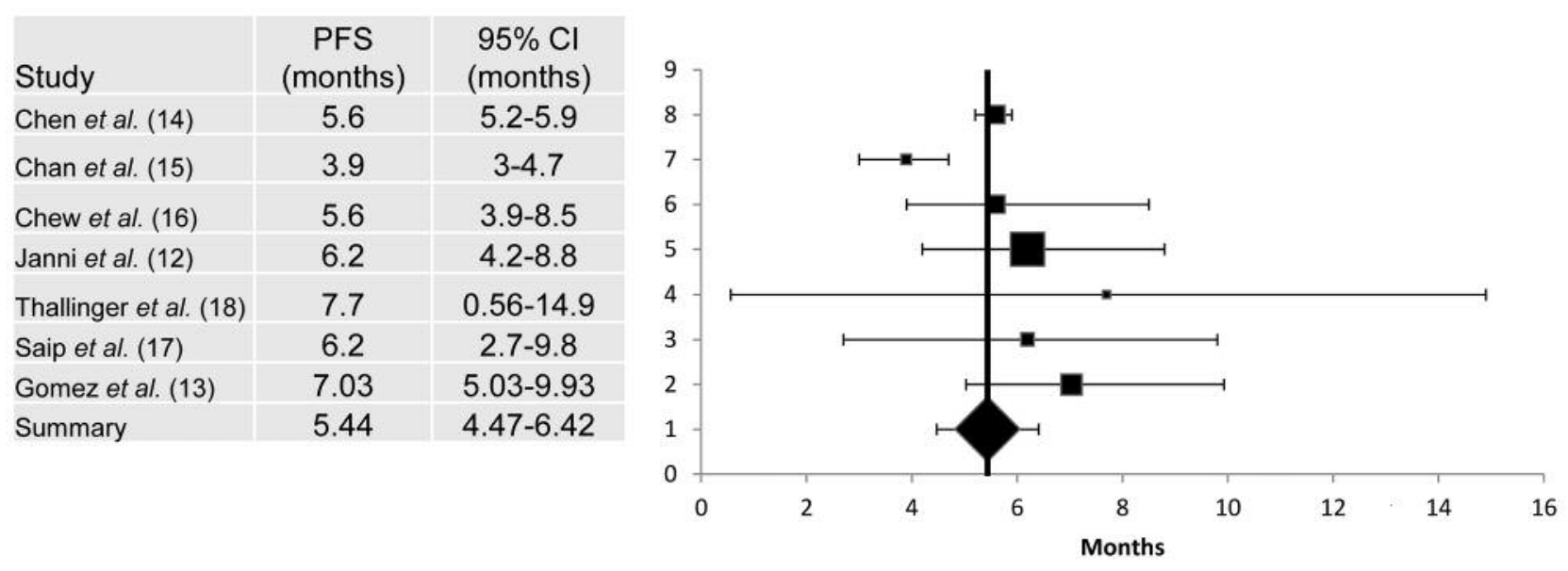

Figure 4. Meta-analysis of progression-free survival (PFS) and 95\% confidence intervals (CI) of the seven studies included. A total of 267 patients with data for the PFS were included. The summary PFS was 5.44 months (95\%CI=4.47-6.42 months).

\begin{tabular}{|l|c|c|}
\hline Study & OS (months) & $95 \% \mathrm{Cl}$ (months) \\
\hline Chan et al. (15) & 9.1 & $0.8-30.2$ \\
\hline Janni et al. (12) & 23.3 & $18.5-31.1$ \\
\hline Thallinger et al. (18) & 23.4 & $16.6-30.1$ \\
\hline Saip et al. (17) & 23.3 & $14.7-31.7$ \\
\hline Gomez et al. (13) & 15 & $9.4-22.4$ \\
\hline Summary & 20.12 & $15.54-24.71$ \\
\hline
\end{tabular}

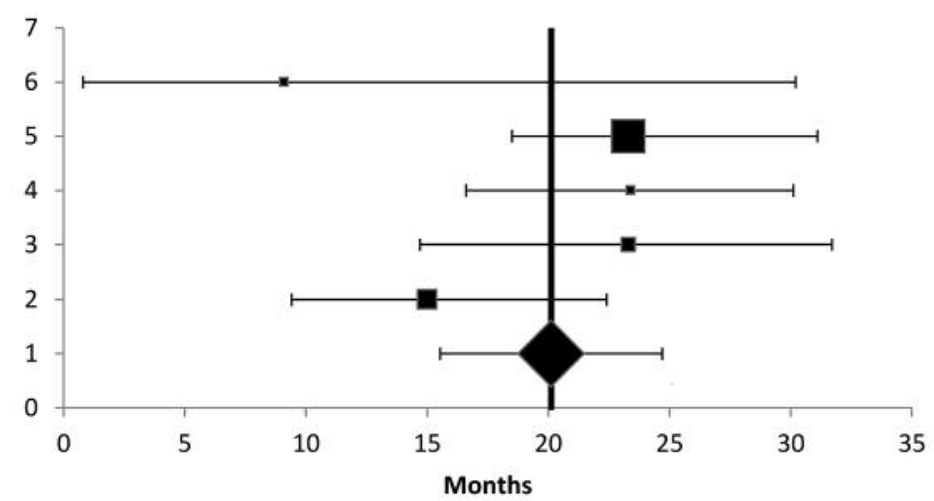

Figure 5. Meta-analysis of overall survival (OS) and 95\% confidence intervals (CI) of the five studies included. Data of a total of 177 patients with information for OS were considered. The pooled OS was 20.12 months (95\%CI=15.54-24.71 months).

included diarrhea $(8.5 \%)$, febrile neutropenia or infection $(5.5 \%)$, nausea $(5.4 \%)$ and mucositis or stomatitis $(4.2 \%)$.

\section{Discussion}

Since the development of trastuzumab, several drugs have become available for the treatment of HER2-positive breast cancer. Despite the fact that, due to the availability of new HER2-directed therapies, the course of HER2-positive breast cancer has improved significantly, many patients still die of metastatic HER2-positive breast cancer, calling for the investigation of newer therapies or new combinations of the already available agents.

Lapatinib, a dual-acting, small-molecule tyrosine kinase inhibitor of HER2 and epidermal growth factor receptor 1 was approved in 2007 in combination with capecitabine for the treatment of patients with metastatic HER2-positive breast cancer who have previously received an anthracycline, a taxane and trastuzumab (19). Although the combination of capecitabine with lapatinib is convenient, both medications being oral, and well-tolerated in general, it may produce some more difficult to manage overlapping adverse effects such as diarrhea and palmar-plantar erythrodysesthesia in a significant minority of patients.

This article reports on a systematic review and metaanalysis of the use of an alternative, effective and acceptably tolerated combination of lapatinib and vinorelbine in patients with metastatic HER2-positive breast cancer. We documented the use of this combination, including toxicity and clinical responses, in the patient population of seven prospective studies. In particular, the fact that efficacy was apparent in patients previousIy treated with trastuzumab- or even lapatinib-based regimens was encouraging. The current pooled analysis of prospective 
Table III. The most common toxicities from the combination treatment of vinorelbine with lapatinib in patients with metastatic her2-human epidermal growth factor receptor 2 (HER2)-positive breast cancer.

\begin{tabular}{|c|c|c|c|c|}
\hline Toxicity & All grades, n (\%) & Grade $3-4, \mathrm{n}(\%)$ & Total patients with data, $\mathrm{n}$ & Studies with data, $\mathrm{n}$ \\
\hline Asthenia/fatigue & $110(41.19 \%)$ & $11(4.11 \%)$ & 267 & 7 \\
\hline Neutropenia & $153(57.3 \%)$ & $87(32.58 \%)$ & 267 & 7 \\
\hline Febrile neutropenia/infection & $12(11 \%)$ & $6(5.5 \%)$ & 109 & 3 \\
\hline Leukopenia & $83(37.2 \%)$ & $16(7.1 \%)$ & 223 & 6 \\
\hline Anemia & $62(30.69 \%)$ & $4(1.98 \%)$ & 202 & 4 \\
\hline Peripheral neuropathy & $13(12.5 \%)$ & $2(1.9 \%)$ & 104 & 2 \\
\hline Nausea & $163(63.17 \%)$ & $14(5.4 \%)$ & 258 & 6 \\
\hline Diarrhea & $167(64.72 \%)$ & $22(8.52 \%)$ & 258 & 6 \\
\hline Cutaneous rash & $86(33.33 \%)$ & $3(1.16 \%)$ & 258 & 6 \\
\hline Pain & $39(28.46 \%)$ & $5(3.64 \%)$ & 137 & 4 \\
\hline Mucositis/stomatitis & $42(19.81 \%)$ & $9(4.24 \%)$ & 212 & 5 \\
\hline
\end{tabular}

series showed a PFS of 5.6 months and DCR of $63.38 \%$, with a favorable toxicity profile and no alopecia, making this an attractive option as another regimen in patients after exposure to trastuzumab or lapatinib-based therapy. The median OS was 20.12 months, a rate well-matched with those from other studies of lapatinib and capecitabine $(20,21)$. Lapatinib in this combination was used mostly according to the regimen described by Geyer et al. (4). Regarding the safety profile, the pooled analysis showed that the incidence of grade 3 or 4 toxicities, including diarrhea, neutropenia and nausea, was less than $10 \%$. In addition, the combination of vinorelbine with lapatinib may, especially valuable in heavily pre-treated patients, have the advantage of being all oral, at least in countries where the oral vinorelbine formulation is available.

There are some potential limitations to this meta-analysis. Firstly, our meta-analysis was based on seven prospective series and some of them had a relatively modest or small sample size. This may have led to an overestimation of the treatment effect compared with studies with larger samples. Secondly, the patient characteristics varied across studies and this heterogeneity, especially the number of previous lines of therapy, may have had a potential impact on our analysis. In addition, some categories of patients, such as those with higher Eastern Cooperative Oncology Group performance status and those with extensive metastatic site involvement, are less well-represented in the populations included in the seven studies.

In summary, our meta-analysis represents the most extensive summary of data regarding the combination of vinorelbine and lapatinib published to date. This combination appears to be an active and well-tolerated regimen in patients with metastatic HER2-positive breast cancer. A PFS of 5.4 months and DCR benefit in excess of $50 \%$ of cases seem particularly compelling arguments that should warrant consideration of this drug combination for this patient population. This combination may serve as an alternative option for the palliative management of pretreated patients with preservation of quality of life. Along with the increasing options for targeting HER2, which besides trastuzumab and lapatinib currently include other antibody-based drugs (pertuzumab and ado-trastuzumab emtansine) and smallmolecule kinase inhibitors (neratinib, tucatinib), this combination will certainly further improve outcomes for these patients who not long ago had few options and a very grim outlook.

\section{Conflicts of Interest}

The Authors declare no conflicts of interest regarding this study.

\section{Authors' Contributions}

IAV conceptualized the study. Both Authors performed the literature search, data analysis and wrote the article.

\section{References}

1 Revillion F, Bonneterre J and Peyrat JP: ERBB2 oncogene in human breast cancer and its clinical significance. Eur J Cancer 34: 791-808, 1998. PMID: 9797688. DOI: 10.1016/S09598049(97)10157-5

2 Press M, Bernstein L, Thomas P, Meisner LF, Zhou JY, Ma Y, Hung G, Robinson RA, Harris C, El-Naggar A, Slamon DJ, Phillips RN, Ross JS, Wolman SR and Flom KJ: HER-2/neu gene amplification characterized by fluorescence in situ hybridization: Poor prognosis in node-negative breast carcinomas. J Clin Oncol 16: 2894-2904, 1997. PMID: 9256133. DOI: $10.1200 / J C O .1997 .15 .8 .2894$

3 Slamon DJ, Leyland-Jones B, Shak S, Fuchs H, Paton V, Bajamonde A, Fleming T, Eiermann W, Wolter J, Pegram M, Baselga $\mathrm{J}$ and Norton L: Use of chemotherapy plus a monoclonal antibody against HER2 for metastatic breast cancer that overexpresses HER2. N Engl J Med 344: 783-792, 2001. PMID: 11248153. DOI: 10.1056/NEJM200103153441101 
4 Geyer CE, Forster J, Lindquist D, Chan S, Romieu CG, Pienkowski T, Jagiello-Gruszfeld A, Crown J, Chan A, Kaufman B, Skarlos D, Campone M, Davidson N, Berger M, Oliva C, Rubin SD, Stein S and Cameron D: Lapatinib plus capecitabine for HER2 positive advanced breast cancer. N Engl J Med 355: 2733-2743, 2006. PMID: 17192538 . DOI: $10.1056 /$ NEJ Moa064320

5 Suzuki Y, Tokuda Y, Saito Y, Ohta M and Tajima T: Combination of trastuzumab and vinorelbine in metastatic breast cancer. Jpn J Clin Oncol 33: 514-517, 2003. PMID: 14623919. DOI: $10.1093 / \mathrm{jjco} / \mathrm{hyg} 101$

6 Stravodimou A, Zaman K and Voutsadakis IA: Vinorelbine with or without trastuzumab in metastatic breast cancer: A retrospective single institution series. ISRN Oncol 2014: 289836, 2014. PMID: 25006504. DOI: 10.1155/2014/289836

7 Sterne JAC, Hernán MA, Reeves BC, Savović J, Berkman ND, Viswanathan M, Henry D, Altman DG, Ansari MT, Boutron I, Carpenter JR, Chan AW, Churchill R, Deeks JJ, Hróbjartsson A, Kirkham J, Jüni P, Loke YK, Pigott TD, Ramsay CR, Regidor D, Rothstein HR, Sandhu L, Santaguida PL, Schünemann HJ, Shea B, Shrier I, Tugwell P, Turner L, Valentine JC, Waddington $\mathrm{H}$, Waters E, Wells GA, Whiting PF and Higgins JP: ROBINSI: A tool for assessing risk of bias in non-randomized studies of interventions. BMJ 355: i4919, 2016. PMID: 27733354. DOI: 10.1136/bmj.i4919

8 Higgins JPT, Thompson SG, Deeks JJ and Altman DG: Measuring inconsistency in meta-analyses. BMJ 327: 557-560, 2003. PMID: 12958120. DOI: $10.1136 /$ bmj.327.7414.557

9 Voutsadakis IA: A systematic review and pooled analysis of retrospective series of eribulin in metastatic breast cancer. Anticancer Drugs 28: 557-564, 2017. PMID: 28263201. DOI: 10.1097/CAD.0000000000000493

10 Wallace BC, Schmid CH, Lau J and Trikalinos TA: MetaAnalyst: Software for meta-analysis of binary, continuous and diagnostic data. BMC Med Res Methodol 9: 80, 2009. PMID: 19961608. DOI: 10.1186/1471-2288-9-80

11 Janni W, Sarosiek T, Karaszewska B, Pikiel J, Staroslawska E, Potemski P, Salat C, Brain E, Caglevic C, Briggs K, Desilvio M, Marini L and Papadimitriou C: A phase II, randomized, multicenter study evaluating the combination of lapatinib and vinorelbine in women with ERBB2-overexpressing metastatic breast cancer. Breast Cancer Res Treat 143: 493-505, 2014. PMID: 24402830. DOI: 10.1007/s10549-013-2828-z

12 Janni W, Sarosiek T, Karaszewska B, Pikiel J, Staroslawska E, Potemski P, Salat C, Brain E, Caglevic C, Briggs K, Mahood K, DeSilvio M, Marini L and Papadimitriou C: Final overall survival analysis of a phase II trial evaluating vinorelbine and lapatinib in women with ERBB2-overexpressing metastatic breast cancer. Breast 24: 769-773, 2015. PMID: 26384789. DOI: 10.1016/j.breast.2015.08.005

13 Gomez HL, Neciosup S, Tosello C, Mano M, Bines J, Ismael G, Santi PX, Pinczowski H, Nerón Y, Fanelli M, Fein L, Sampaio C, Lerzo G, Capó A, Zarba JJ, Blajman C, Varela MS, Martínez-Mesa $\mathrm{J}$, Werutsky $\mathrm{G}$ and Barrios $\mathrm{CH}$ : A phase II randomized study of lapatinib combined with capecitabine, vinorelbine or gemcitabine in patients with HER2-positive metastatic breast cancer with progression after a taxane (Latin American Cooperative Oncology Group 0801 Study) Clin Breast Cancer 16: 38-44, 2016. PMID: 26642810. DOI: 10.1016/j.clbc.2015. 10.005
14 Chen T W-W, Yeh DC, Chia TY, Lin CH, Chow LW, Chang DY, Hsieh YY, Huang SM, Cheng AL, Lu YS and Consortium TBC: A phase I/II study of the combination of lapatinib and oral vinorelbine in HER2-positive metastatic breast cancer. Jpn J Clin Oncol 48: 242-247, 2018. PMID: 29315394. DOI: 10.1093/ jjco/hyx188

15 Chan A, Shannon C, De Boer R, Baron-Hay S, Redfern A, Bauwens A, Craft P, Webb S, Townsend A and Kotasek D: Phase II, open-label trial of lapatinib and vinorelbine in women with previously treated HER2-positive metastatic breast cancer. Asia Pac J Clin Oncol 10: 368-375, 2014. PMID: 25351929. DOI: 10.1111/ajco. 12292

16 Chew HK, Schwartzberg L, Badarinath S, Rubin P, Shumaker G, Daugherty J, DeSilvio M and Mahoney J: Phase II study of lapatinib in combination with vinorelbine, as first or second-line therapy in women with HER2-overexpressing metastatic breast cancer. Spingerplus 3: 108, 2014. PMID: 26034656. DOI: 10.1186/2193-1801-3-108

17 Saip P, Eralp Y, Sen F, Karaca H, Ozkan M, Cetin B, Benekli M, Kucukoner M, Isikdogan A, Un O, Basaran G and Onur H: Phase II study of lapatinib in combination with vinorelbine in patients with HER2 positive recurrent or metastatic breast cancer: a multicentric Turkish Oncology Group (TOG) trial. Breast 22: 628-633, 2013. PMID: 23954396. DOI: 10.1016/ j.breast.2013.07.048

18 Thallinger C, Lang I, Kuhar CG, Bartsch R, Singer CF, Petruzelka L, Melichar B, Knittelfelder R, Brodowicz T and Zielinski C: Phase II study of the efficacy and safety of lapatinib administered beyond disease progression and combined with vinorelbine in HER-2/neu-positive advanced breast cancer: results of the CECOG LaVie trial. BMC Cancer 16: 121, 2016. PMID: 26887956. DOI: 10.1186/s12885-016-2171-y

19 Ryan Q, Ibrahim A, Cohen MH, Johnson J, Ko CW, Sridhara R, Justice R and Pazdur R: FDA drug approval summary: Lapatinib in combination with capecitabine for previously treated metastatic breast cancer that overexpresses HER-2. Oncologist 13: 11141119, 2008. PMID: 18849320. DOI: 10.1634/ theoncologist.20080816

20 Cameron D, Casey M, Press M, Lindquist D, Pienkowski T, Romieu CG, Chan S, Jagiello-Gruszfeld A, Kaufman B, Crown J, Chan A, Campone M, Viens P, Davidson N, Gorbounova V, Raats JI, Skarlos D, Newstat B, Roychowdhury D, Paoletti P, Oliva C, Rubin S, Stein S and Geyer CE: A phase III randomized comparison of lapatinib plus capecitabine versus capecitabine alone in women with advanced breast cancer that has progressed on trastuzumab. Breast Cancer Res Treat 112: 533-543, 2008. PMID: 18188694. DOI: 10.1007/s10549-007-9885-0

21 Cameron D, Casey M, Oliva C, Newstat B, Imwalle B and Geyer CE: Lapainib plus capecitabine in women with HER2 positive advanced breast cancer: Final survival analysis of a phase III randomized trial. Oncologist 15: 924-934, 2010. PMID: 20736298. DOI: 10.1634/theoncologist.2009-0181

Received April 3, 2019

Revised May 16, 2019

Accepted May 20, 2019 